\title{
Learning and retention of sucrose taste aversion in weanling rats
}

\author{
JOSEPH J. FRANCHINA, GARY C. DOMATO, and DAVID McCLEESE \\ Virginia Polytechnic Institute and State University, Blacksburg, Virginia 24061
}

\begin{abstract}
Sixty rat pups, 21 days old, drank $9 \%$ sucrose and then received a single injection of distilled water or $.3, .6,1.8$, or $3.0 \mathrm{mEq}$ of lithium chloride ( $\mathrm{LiCl})$. Testing with a two-bottle choice procedure showed that sucrose taste aversion occurred reliably following injections of 1.8 and $3.0 \mathrm{mEq}$ of $\mathrm{LiCl}$, but not following .3- or .6- $\mathrm{mEq}$ injections. In Experiment 2, 80 rat pups, 21 days old, drank $9 \%$ sucrose and received an injection of LiCl $(3.0 \mathrm{mEq})$ or distilled water and then were tested for taste aversion $24,48,72$, or $168 \mathrm{~h}$ later. Aversion effects were reliable at each retention interval; the magnitude of aversion was invariant across intervals.
\end{abstract}

Recent studies of taste aversion learning have shown that when the conditions of training and testing are appropriate, young rats 22 to 29 days old learn to inhibit consummatory responding toward a taste stimulus that previously accompanied toxicosis (e.g., Ader \& Peck, 1977; Baker, Baker, \& Kesner, 1977; Grote \& Brown, 1971b; Klein, Domato, Hallstead, Stephens, \& Mikulka, 1975). However, Baker et al. (1977) and Klein et al. (1975) have indicated that although taste aversion effects were demonstrable with young rats, these effects seemed more labile than they appeared to be for older rats, 80 days of age. That is, conditions that yielded reliable taste aversion effects in adult rats yielded only marginal effects in younger rats. Unfortunately, the relatively sparse amount of information about the parameters of taste aversion for weanling rats makes it difficult to ascertain the basis for the weanlings' performance in aversion learning. One apparently potent taste aversion variable whose effects have been reported for adult rats (Nachman \& Ashe, 1973) but not for weanlings is the intensity (concentration) of the toxicosis-inducing agent. Nachman and Ashe (1973) showed that for adult rats, 60 days old, taste aversion increased reliably with increasing milleequivalents (mEq) of lithium chloride $(\mathrm{LiCl})$ up to $3.0 \mathrm{mEq}$. Since there are no dose-response data available for infant rats, Experiment 1 investigated the effects of injecting .3-, .6-, 1.8-, or $3.0-\mathrm{mEq} \mathrm{LiCl}$ on taste aversion in rats, 21 days old at injection.

\section{EXPERIMENT 1}

\section{Method}

Subjects. The subjects were 60 Long-Evans-derived hooded rat pups (both genders) from the animal colony maintained by the Department of Psychology at Virginia Polytechnic Institute

These data were reported at the meeting of the Midwestern Psychological Association, Chicago, May 1977. The authors thank W. B. Pavlik for reading an earlier draft of the paper. and State University. Three to 5 days after birth, the size of each litter was culled to eight pups. Each litter remained with the dam until Day 1 of the experiment, 16 days postpartum.

Design and Procedure. On Day 1 the rat pups were housed individually in single hanging cages in a room $2.4 \times 2.4 \times 3.0 \mathrm{~m}$. Room temperature was approximately $76^{\circ} \mathrm{F} \pm 2^{\circ} \mathrm{F}$; illumination was held constant at approximately $80 \mathrm{fc}$. Wet mash and tap water were available ad lib in the home cage for the first $24 \mathrm{~h}$.

On Days 2, 3, 4, and 5, each pup received 1-h daily access to tap water; the wet mash was made progressively drier over days until on Day 5 only dry ground chow served as food. On Day 6 the rat pups, 21 days old, were randomly assigned to injection conditions $(n=12)$. Each pup received $1-h$ access to $9 \%$ sucrose (weight/volume), and within $15 \mathrm{~min}$ after the end of the drinking period, each received an intraperitoneal injection of $.3, .6$, or $1.8 \mathrm{mEq}$ of .15 -molar $\mathrm{LiCl}$, or $3.0 \mathrm{mEq}$ of .30 -molar $\mathrm{LiCl}$, or $12 \mathrm{ml} / \mathrm{kg}$ of distilled water. Beginning $24 \mathrm{~h}$ after injection, each rat was tested for sucrose taste aversion with a two-bottle choice procedure: One bottle contained $9 \%$ sucrose, the other, tap water. Each pup received nine 1-h test periods, one period every $24 \mathrm{~h}$. The measure of performance was the amount drunk (in milliliters) from each bottle, as calculated by the difference in the bottle's weight between pre- and posttest weighings. A sucrose preference index (Ader \& Peck, 1977) was calculated for each test day: sucrose intake relative to total fluid intake, Suc/(Suc + Hoh $) \times 100$.

To evaluate the effects of the injection conditions on the growth of the young animals, each pup was weighed daily throughout the experiment. The weight data showed that all rat pups lost weight (range: $.5-4.0 \mathrm{~g}$ ) on the first 2 days following separation from the dam. Beginning on Day 3 , however, the pups' weights increased monotonically over days and were nondifferential across injection conditions. Five pups died within 3 days following separation from the dam; no pups died following injection. Deceased rats were replaced.

\section{Results}

Mean sucrose intakes on the injection day (Day 6) were 9.3, 9.2, 9.0, 9.9, and $9.3 \mathrm{ml}$ for $\mathrm{mEq}$ Groups .3, $.6,1.8$, and 3.0 and for distilled water (DW) controls, respectively. Analysis of variance of these data revealed no reliable difference among groups $(\mathrm{F}<1)$. The sucrose preference data (Figure 1) showed negligible differences among .3- and .6-mEq groups and DW controls, and a decidedly lower sucrose preference for 1.8 - and $3.0-\mathrm{mEq}$ 


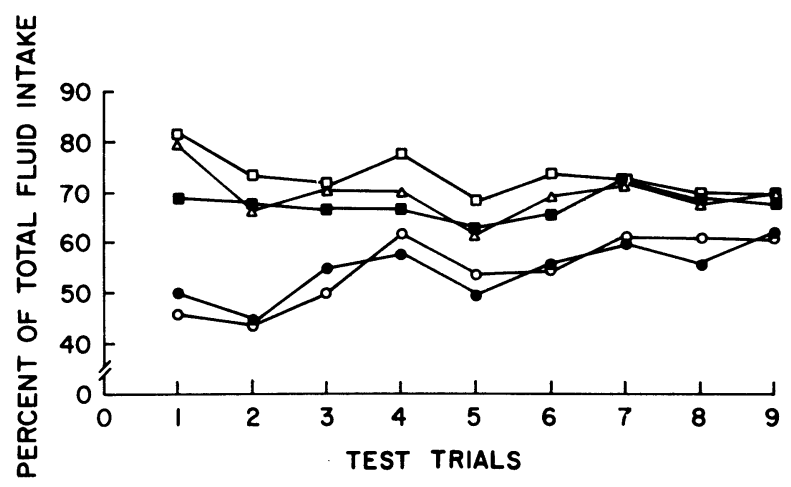

Figure 1. Amount of sucrose intake as a percentage of total fluid intake (sucrose plus water) over nine test trials for weanlings injected with .3 (squares, open), .6 (squares, closed), 1.8 (circles, open), and $3.0 \mathrm{mEq}$ (circles, closed) of $\mathrm{LiCl}$ or with distilled water (triangles, open).

groups. These effects persisted throughout testing. Analysis of variance over all the data of Figure 1 yielded a reliable effect for injection condition and a reliable interaction of Injection Condition by Test Trials $[F(4,55)=9.35, F(32,440)=2.76$, ps $<.001]$. Simpleeffects analyses of variance for the data of Test Trials 1 and 9 separately yielded a highly reliable effect for injection condition on Test Trial $1[\mathrm{~F}(4,55)=16.65$, $\mathrm{p}<.001$ ] and only a marginally reliable effect for injection condition on Test Trial $9[\mathrm{~F}(4,55)=2.42$, $\mathrm{p}=.059]$. Scheffé comparisons for Test Trial 1 performance showed that Groups DW, $.3 \mathrm{mEq}$, and $.6 \mathrm{mEq}$ did not differ reliably from each other but did differ reliably from Groups $1.8 \mathrm{mEq}$ and $3.0 \mathrm{mEq}$ (ps <.05). Groups 1.8 and 3.0 did not differ reliably from each other ( $\mathrm{ps}>$ .10). A trials by subjects analysis of the data for each group separately also indicated that Groups DW, $.3 \mathrm{mEq}$, and $.6 \mathrm{mEq}$ showed no reliable change in performance over test trials $(\mathrm{F}<1)$. The performance of $\mathrm{mEq}$ Groups 1.8 and 3.0 did change reliably over trials $[\mathrm{Fs}(8,88)=$ 5.73 and $5.89, p<.01]$. As Figure 1 shows, sucrose preference increased for 1.8 - and $3.0-\mathrm{mEq}$ groups over Test Trials 1-9.

The results of the sucrose preference index were corroborated by the data of absolute sucrose intake. On Test Trial 1 mean sucrose intakes were 6.8, 6.4, 5.8, 3.5 , and $3.3 \mathrm{ml}$, respectively, for Groups DW, .3, .6, 1.8, and $3.0 \mathrm{mEq}$. This relationship generally persisted throughout testing.

\section{Discussion}

This experiment showed that the demonstration of taste aversion in weanling rats depended upon the $\mathrm{mEq}$ of $\mathrm{LiCl}$ injected. No reliable evidence of aversion appeared at .3 and $.6 \mathrm{mEq}$; reliable aversion effects appeared at 1.8 and $3.0 \mathrm{mEq}$. These data suggested an all-or-none relationship between injection conditions and taste aversion for weanling rats rather than the more continuous function that Nachman and Ashe (1973) reported for adult rats.

The apparent absence of aversion effects at .3 and $.6 \mathrm{mEq}$ in the present study was inconsistent with Nachman and Ashe (1973). Those investigators showed (Experiment 1, Figure 1) that an injection of $.3-\mathrm{mEq} \mathrm{LiCl}$ reduced sucrose intake by approximately $50 \%$ relative to controls, and an injection of $.6 \mathrm{mEq}$ reduced sucrose intake even further. The disparity of results between the present experiment and Nachman and Ashe (1973) may seem puzzling because of the similarities in injection procedures between the studies. Both experiments administered a single intraperitoneal injection of the same $\mathrm{mEq}$, $.3, .6$, and 1.8, of .15-molar $\mathrm{LiCl}$ following access to comparable levels of a sucrose flavor $(15 \%$ sucrose in Nachman \& Ashe, 9\% sucrose in this study). Admittedly, Nachman and Ashe (1973) tested for taste aversion with a single-bottle procedure and the present experiment used a two-bottle choice procedure. This procedural difference may have been incidental, however, because the two-bottle test procedure used in this experiment has been shown to be more sensitive in detecting aversion effects (Dragoin, McCleary, \& McCleary, 1971; Grote \& Brown, 1971a; Klein et al., 1975) and thus should have been more likely to reveal group differences than was the one-bottle test used in Nachman and Ashe (1973). Clearly, the more narrow alignment of group differences appeared in the present study, which used the presumably more sensitive test for aversion effects.

A prominent difference between the present procedures and those of Nachman and Ashe (1973) was the duration of access to the flavor stimulus prior to $\mathrm{LiCl}$ injection and, consequently, the length of delay between flavor exposure and toxicosis. Nachman and Ashe (1973) provided 10-min access to sucrose followed by $\mathrm{LiCl}$ injection within $2-5 \mathrm{~min}$ after the end of the access period. The present study provided $1 \mathrm{~h}$ of sucrose access followed by $\mathrm{LiCl}$ injection within $15 \mathrm{~min}$ after the end of the access period. If the pups in the present study drank sucrose in the early part of the access period, then the length of the period and the ensuing 15-min interval may have constituted too long a delay between flavor exposure and toxicosis to permit the demonstration of aversion effects at all but the highest injection levels. Baker et al. (1977) showed that length of the flavor access period and length of delay between flavor exposure and toxicosis interact to affect the strength of taste aversion in infant and adult rats. The same interaction of temporal factors in the present experiment could have contributed to the differences in injection effects between this study and Nachman and Ashe (1973).

It was unlikely that the aversion effects of the present experiment were due to a general suppression of drinking behavior or to protracted illness effects following toxicosis. Evaluation of total fluid intake in each test session (water intake plus sucrose intake) showed no reliable differences between injection groups. It was also unlikely that the difference in aversion between high- (1.8- and 3.0-mEq) and low- (.3- and .6-mEq) injection conditions reflected differences in injection volume. Group DW received an injection volume of $12 \mathrm{ml} / \mathrm{kg}$, which was more comparable to those of the high-LiCl groups than to those of the low groups. Yet performance of Group DW differed reliably from that of the high- $\mathrm{LiCl}$ groups and not from that of the low-LiCl groups. This finding of negligible effects of injection volume was highly consistent with the data of Nachman and Ashe (1973).

\section{EXPERIMENT 2}

It has been well documented that infant rats exhibit relatively rapid forgetting of instrumental passive avoidance behavior (Campbell \& Coulter, 1976). According to Campbell, Misanin, White, and Lytle (1974, Experiment 3), weanling rats, 16 to 25 days of age, showed rapid forgetting of shock-instigated passive avoidance over intervals of up to 22 days after training, but the retention function appeared to have been established within 7 days after training. In the case of 
consummatory response withholding in a taste aversion paradigm, Baker et al. (1977) showed reliable aversion effects in infant rats tested $4 \mathrm{~h}$ and $72 \mathrm{~h}$ after toxicosis. Klein, Mikulka, Domato, and Hallstead (1976) reported that rats, poisoned at 28 days of age, showed reliable aversion effects 1 day or 28 days later. Conversely, Ader and Peck (1977) found no reliable evidence of retention of taste aversion in weanling rats tested in isolation 60 days after aversion training. Only Klein et al. (1976) have reported weanlings' retention of taste aversion at two independently assessed temporal intervals. Since there seems to be little information about weanling rats' retention of taste aversion over relatively short temporal intervals and the data of Campbell et al. (1974) seemed provocative, the present experiment studied retention of taste aversion at intervals of $24,48,72$, and $168 \mathrm{~h}$ (7 days) following toxicosis.

\section{Method}

Subjects. The subjects were 80 Long-Evans-derived hooded rat pups (both genders) from the same colony source as those in Experiment 1.

Design and Procedure. The procedures for culling litters and those for injections and testing were the same as those described for Experiment 1. On Day 6 of the experiment, the rat pups, 21 days old, were randomly assigned to cells $(n=10)$ of a factorial design that combined two injection conditions (3.0 mEq of .30-molar $\mathrm{LiCl}$ or $10 \mathrm{ml} / \mathrm{kg}$ of distilled water) and four retention intervals $(24,48,72$, and $168 \mathrm{~h})$. During the retention intervals, the rats were maintained on ad-lib access to ground chow and 1-h daily access to tap water in the home cage. Testing for taste aversion consisted of 1-h access to a twobottle choice procedure on each of 3 test days, as described in Experiment 1. The measure of performance was amount of fluid (in milliliters) drunk from each bottle. A sucrose preference score was calculated as in Experiment 1. Daily weighings of each rat pup again failed to show adverse effects of $\mathrm{LiCl}$ injections on the rat's growth, at least in terms of body weight.

\section{Results}

Mean sucrose intakes on the injection day (Day 6) were $7.7,8.3,8.0$, and $7.9 \mathrm{ml}$ for $24-, 48-, 72-$, and 168-h groups, respectively, in the $\mathrm{LiCl}$ condition and $7.9,7.7,7.8$, and $8.2 \mathrm{ml}$ for the same order of groups in the DW condition. Analysis of variance over all the data of Day 6 yielded no reliable group differences $(\mathrm{Fs}<1)$.

Figure 2 shows that on Test Trial 1 sucrose preference was lower for $\mathrm{LiCl}$ groups than for $\mathrm{DW}$ controls at each retention interval, the magnitude of this difference being roughly constant across intervals. Analysis of variance of the data of Test Trial 1 revealed a reliable effect for injection condition $[F(1,72)=15.72, p<.001]$ and no reliable effect for retention interval or for the Retention Interval by Injection Condition interaction ( $F s=1.09$ and 1.00 , respectively). Performance on Test Trials 2 and 3 showed the same effects for injection condition and retention intervals as those shown on Test Trial 1. The measure of absolute sucrose intake on Test Trial 1 corroborated the conclusions of the sucrose preference

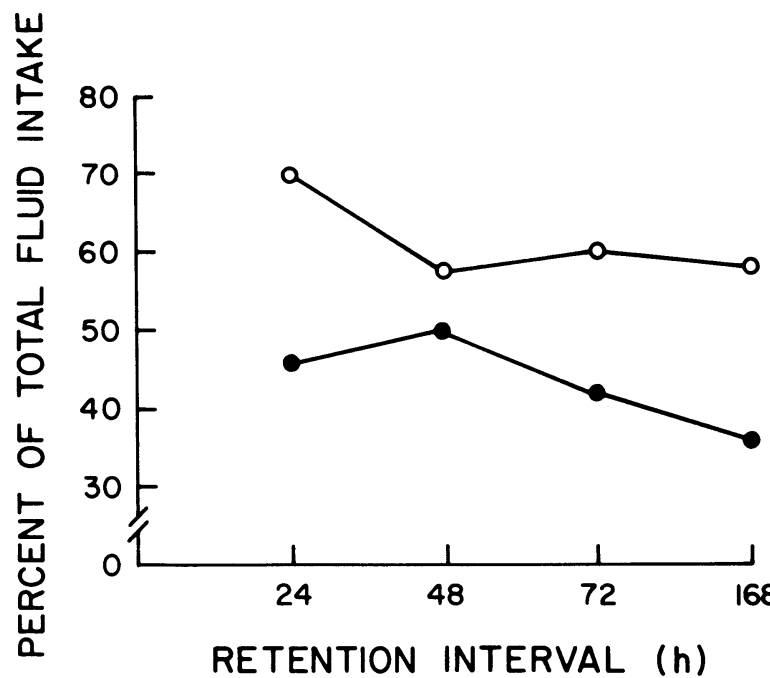

Figure 2. Amount of sucrose intake as a percentage of total fluid intake (sucrose plus water) on Test Trial 1 for weanlings injected with $3.0 \mathrm{mEq}$ of $\mathrm{LiCl}$ (circles, closed) or with distilled water (circles, open) and tested $24,48,72$, or $168 \mathrm{~h}$ later. index. Mean amounts of sucrose drunk on Test Trial 1 were $2.7,3.7,2.8$, and $2.9 \mathrm{ml}$ for 24-, 48-, 72-, and 168-h groups in the $\mathrm{LiCl}$ condition and 5.5, 5.2, 5.2, and $5.6 \mathrm{ml}$ for the same order of groups in the DW condition.

\section{Discussion}

In Experiment 2 weanling rats, trained at 21 days of age, showed invariant retention of sucrose taste aversion for intervals up to $168 \mathrm{~h}$ ( 7 days) after training. These results were consistent with those from Klein et al. (1976), which showed retention of taste aversion in weanling young rats 1 day and 28 days after aversion training. However, the present data were inconsistent with those from Campbell et al. (1974) that showed rapid forgetting of instrumental passive avoidance behavior over the same 7-day period.

Several explanations of the present data seem possible (see Klein et al., 1974). Briefly, invariant retention effects may be idiosyncratic to taste aversion procedures. The gustatory experience of sucrose and the subsequent toxicosis may constitute relatively unique happenings in the rat's history and thus may be highly resistant to interference from events interpolated during the retention intervals. Another possibility is that the interoceptive conditioning of gustatory stimuli and gastrointestinal events might yield more robust effects that are more likely to endure over time than are the effects of exteroceptive conditioning, such as those in passive avoidance shock situations. Finally the consummatory response involved in taste aversion might constitute a relatively primitive behavioral system that develops early after birth on the basis of minimal information. Instrumental responding, however, might reflect a more slowly developing behavioral system that requires more complex information for acquisition and retention. Thus, the present findings of invariant retention of consummatory response withholding relative to the apparently rapid forgetting of instrumental response withholding in Campbell et al. (1974) might have been due to differences between classes of behavior (consummatory vs. instrumental) or due to the primacy of the response system underlying consummatory behavior relative to that for instrumental behavior. Whether invariant retention effects will occur for adult rats in taste aversion and whether 
invariant retention will be displayed at long retention intervals (e.g., 10 weeks) for weanling rats are questions for further investigation.

\section{REFERENCES}

Ade R, R., \& Peck, J. H. Early learning and retention of a conditioned taste aversion. Developmental Psychobiology, 1977, 10, 213-218.

Baker, L. J., BAKer, T. B., \& Kesner, R. P. Taste aversion learning in young and adult rats. Journal of Comparative and Physiological Psychology, 1977, 91, 1168-1178.

Campbell, B. A., \& Coulter, X. Ontogenesis of learning and memory. In M. R. Rosenweig (Ed.), Neural mechanisms of learning and memory. Cambridge, Mass: MIT Press, 1976.

Campbell, B. A., Misanin, J. R., White, B. C., \& Lytle, L. D. Species differences in ontogeny of memory: Support for neural maturation as a determinant of forgetting. Journal of Comparative and Physiological Psychology, 1974, 87, 193-202.

Dragoin, E., McCleary, G. E., \& McCleary, P. A. A comparison of two methods of measuring conditioned taste aversion.
Behavior Research Methods \& Instrumentation, 1971, 3, 309-310. Grote, F. W., JR., \& Brown, R. T. Conditioned taste aversions: Two-stimulus tests are more sensitive than one-stimulus tests. Behavior Research Methods \& Instrumentation, 1971, 3, 311-312. (a)

Grote, F. W., JR., \& Brown, R. T. Rapid learning of passive avoidance by weanling rats: Conditioned taste aversion. Psychonomic Science, 1971, 25, 163-164. (b)

Klein, S. B., Domato, G. C., Hallstead, C., Stephens, I., \& MikUlKA, P. J. Acquisition of a conditioned aversion as a function of age and measurement technique. Physiological Psychology, 1975, 3, 379-384.

Klein, S. B., Mikulka, P. J., Domato, G. C., \& Hallstead, C. Retention of internal experiences in juvenile and adult rats. Physiological Psychology, 1976, 5, 63-65.

Nachman, M., \& Ashe, J. H. Learned taste aversions in rats as a function of dosage, concentration and route of administration of LiCl. Physiology \& Behavior, 1973, 10, 73-78.

(Received for publication April 19, 1979.) 